\title{
Varis Dışı Üst Gastrointestinal Kanamalı Hastaların ve Mevsimsel Dağılımının Analizi
}

\section{Analysis of Non-variceal Upper Gastrointestinal Hemorrhagic Patients and Seasonal Distribution}

\author{
Mehmet Önder EKMEN ${ }^{1}(\mathbb{D})$, Ahmet UYANIKOĞLU ${ }^{1}(\mathbb{D})$, Savaş Cumali EFE ${ }^{1}$ (D) , Necati YENiCE $^{1}$ (D) \\ ${ }^{1}$ Harran üniversitesi, Tıp Fakültesi, Gastroenteroloji Bilim Dalı, Şanlıurfa, TÜRKiYE
}

öz.

Amaç: Varis dışı üst gastrointestinal sistem (GiS) kanamasıyla son 1 yıl içinde başvuran hastaların temel demografik özelliklerini ve kanamanın mevsimsel dağılımını değerlendirmeyi amaçladık.

Materyal ve Metod: Gastroenteroloji kliniğimize 1 Mayıs 2019 ile 30 Nisan 2020 tarihleri arasında başvuran ve endoskopik tanısında varis dışı üst Gis kanaması olan hasta dosyaları geriye yönelik tarandı. Hastaların demografik bulguları ve endoskopik verileri kaydedildi.

Bulgular: Çalışmaya toplam 231 hasta dahil edildi. Bunlardan 142 'si (\%61.5) erkek, 54'ü (\%38.5) kadın, yaş ortalaması $52.72 \pm 14.25$ idi. Hastalarda en sık endoskopik patoloji olarak duodenum ülseri saptandı (\%33.3). Başvuru tarihleri 3'er aylık dönemler halinde incelendi. En çok başvuru \%27.27 ile haziran-temmuz-ağustos, en az başvuru \%20.3 ile aralık-ocak-şubat aylarında görüldü.

Sonuç: Varis dışı üst Gis kanamanın en sık nedeni duodenal ülserdir. En sık kanama başvurusu yaz, en az kış aylarında görülmektedir.

Anahtar kelimeler: Üst GiS Kanama, Endoskopi, Duodenal ülser

\section{Abstract}

Background: We aimed to evaluate the basic demographic characteristics and seasonal distribution of bleeding in patients presenting with non-varicose upper gastrointestinal system (GIS) bleeding within the last 1 year.

Materials and Methods: Between 1 May 2019 and 30 April 2020, the files of patients who were admitted to our gastroenterology clinic and had non-variceal upper GIS bleeding in endoscopic diagnosis were retrospectively reviewed. Demographic findings and endoscopic data of the patients were recorded.

Results: A total of 231 patients were included in the study. Of these, 142 (61.5\%) were male and $54(38.5 \%)$ were female. The mean age of the patients was $52.72 \pm 14.25$ years. Duodenal ulcer was detected as the most common endoscopic pathology in patients. The highest admission ratio was in June-July-August with a percentage of $27.27 \%$, while the least admission ratio was in December-January-February with a percentage of $20.3 \%$.

Conclusions: The most common cause of non-varicose upper GIS bleeding is the duodenal ulcer. The highest admission ratio is seen in summer, while the least admission ratio is seen in winter.

Key Words: Upper GIS Bleeding, Endoscopy, Duodenal ulcer 


\section{Giriş}

Üst özofagus ile duodenumdaki Treitz ligamenti arasındaki bölgeden olan kanama,üst gastrointestinal sistem (GiS) kanaması olarak tanımlanır (1).Gastrointestinal sistem kanamaları,hastalarda morbidite ve bazen de mortaliteye yol açtığı gibi ciddi ekonomik yükü de beraberinde getirir. Endoskopik tedavi yöntemleri ile hastanede yatış ve ölüm oranlarında belirgin azalma olmuştur(2,3).

Ülkemizde üst Gastrointestinal kanamaların en sık iki nedeni peptik ülser hastalığı ve eroziv gastrittir (4). Özofagogastroduodenoskopi; kanamaya sebep olan lezyonun ve aktif kanama olup olmadığının tespit edilmesi ve kanamaya yol açan lezyonların tedavi edilmesinde değerli bir yöntemdir (5).

ilk 24 saatte tanısal endoskopi yapılan ve gerektiğinde endoskopik tedavi uygulanan üst Gis kanamalı hastalarda erken tanısal endoskopi; hastaların hastanede kalış süresini, yeniden kanama riskini, cerrahi müdahale riskini ve mortaliteyi azaltır (6). Bu çalışmada varis dışı üst GiS kanamalı hastalarımızın demografik özelliklerini ve mevsimsel dağılımının incelemesi amaçlanmıştır.

\section{Materyal ve Metot}

Son 1 yıllık süreçte (1 Mayıs 2019 ile 30 Nisan 2020 tarihleri arasında) acil servisten ve polikliniklerden üst Gis kanama ön tanısı ile Harran Üniversitesi Tıp Fakültesi Hastanesi, Gastroenteroloji Kliniği Endoskopi Ünitesine yönlendirilen hastalara yapılan endoskopi sonuçları retrospektif olarak tarandı. Varis kanamaları değerlendirmeye alınmadı. Hastaların tümüne acile veya polikliniğe başvurduğu 24 saat içinde hastalara lokal sedasyon ile (lidokain sprey) üst gastrointestinal endoskopi yapıldı. Endoskopide kanama yeri, ülser zemininde görünür damarın varlığı, lezyon tabanında siyah leke, yapışık pıhtı veya kanayan lezyon olup olmadığı, hastaların yaşı ve cinsiyeti değerlendirilmeye alındı.

Çalışma için Harran Üniversitesi Klinik Araştırmalar Etik Kurulundan etik onam alındı (17/08/2020 tarih ve HRU/20.14.01 sayılı karar)

Çalışmada hastaların demografik özellikleri yanı sıra hasta sayısının mevsimsel dağılımı değerlendirildi. İstatistiksel analizler için "SPSS for Windows Versiyon 11 "bilgisayar programı kullanıldı. Kategorik değişkenler sayı ve yüzde ile, sürekli değişkenler ise ortalama \pm standart sapma olarak ifade edildiler.

\section{Bulgular}

Çalışmamızda toplam 231 hasta incelendi. Bunlardan 142 'si (\%61.5) erkek (E), 54'ü (\%38.5) kadındı (K). Hastaların yaş ortalaması $52.72 \pm 14.25$ (K: $54.53 \pm 20.39, \mathrm{E}: 50.16$ \pm 17.43 ), yaş dağılımı ise $18-96$ yaş idi . Hastalardan, 77 'sinde (E:42, K:35) duodenal ülser, 74'ünde (E:58, K:16) eroziv gastrit, 34'ünde ( $E: 16, K: 18)$ antral gastrit, 24'ünde (E:15, K:9) mide ülseri, 7'sinde (E:3, K:4) özofagus ülseri/özofajit, 7 'sinde (E:4, $K: 3)$ malignite, $5^{\prime}$ inde (E:2, $K: 3$ ) anjiodisplazi, 3'ünde $(E: 2, K: 1)$ hemobili saptanmıştır
(Tablo 1, Şekil 1).

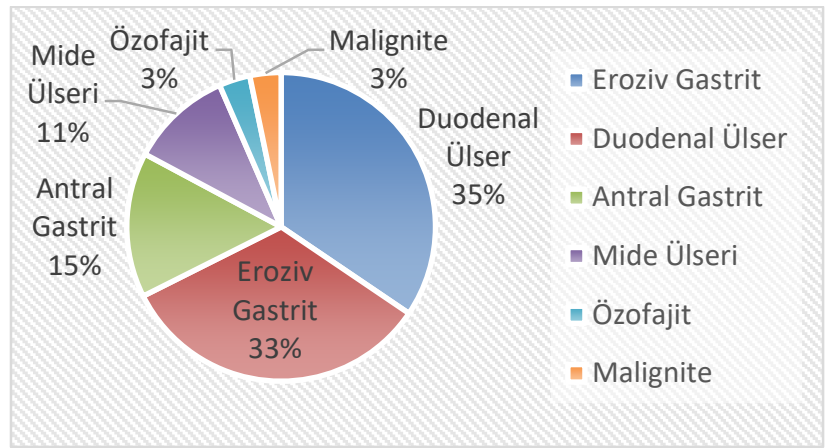

Şekil 1. Üst gastrointestinal sistem kanaması nedenlerinin dağılımı Lezyonların Yüzdelik Görülme Sıklığı

Tablo 1. Üst gastrointestinal sistem kanaması nedenleri ve cinsiyete göre dağılımı

\begin{tabular}{lccc}
\hline Tanı & Hasta Sayısı & Erkek & Kadın \\
\hline & & & \\
Duodenal Ülser & 77 & 42 & 35 \\
Eroziv Gastrit & 74 & 58 & 16 \\
Antral Gastrit & 34 & 16 & 18 \\
Mide Ülseri & 24 & 15 & 9 \\
Özofajit & 7 & 3 & 4 \\
Malignite & 7 & 4 & 3 \\
Anjiodisplazi & 5 & 2 & 3 \\
Hemobili & 3 & 2 & 1 \\
\hline Toplam & $\mathbf{2 3 1}$ & $\mathbf{1 4 2}$ & $\mathbf{8 9}$ \\
\hline
\end{tabular}

3'er aylık periyotlar halinde mevsimlere göre başvuru dö nemleri incelendi . En fazla başvuru \%27.27 ile yaz aylarında(Haziran-Temmuz-Ağustos) görüldü. Sonbahar aylarında(Eylül-Ekim-Kasım) \%26.83, ilkbahar aylarında(MartNisan-Mayıs) \%25.54, kış aylarında(Aralık-Ocak-Şubat) \%20.3 oranında başvuru gerçekleştirmiştir (Şekil 2).

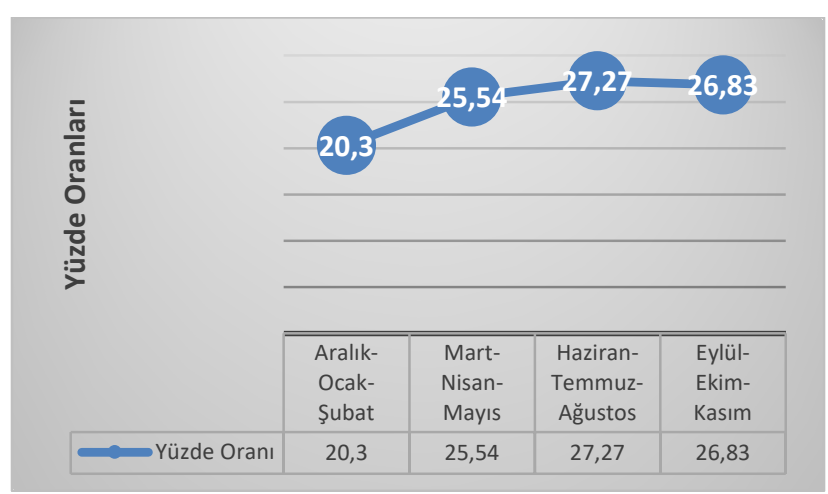

Şekil 2. Üst gastrointestinal sistem kanaması mevsimsel dağııımı

Tüm hastalara acile veya polikliniğe başvuruyu takip eden 24 saat içinde endoskopi yapıldı. Endoskopi sonuçlarında peptik ülser saptanan hastalar Forrest sınıflamasına göre değerlendirildi. Sırasıyla 2 hasta (\%2.6) Forrest 1A, 6 hasta (\%7.8) Forrest 1B, 17 hasta (\%22) Forrest 2A, 6 hasta (\%7.8) Forrest 2B, 2 hasta (\%2.6) Forrest $2 \mathrm{C}$ ve 44 hasta (\%57.2) Forrest 3 olarak tespit edildi (Tablo 2). 
Tablo 2. Forrest sınıflamasına göre peptik ülser dağılımı

\begin{tabular}{lcc} 
Forest Sınıflaması & Sayı(n) & Yüzde(\%) \\
\hline Forest 1A & 2 & 2.6 \\
Forest 1B & 6 & 7.8 \\
Forest 2A & 17 & 22 \\
Forest 2B & 6 & 7.8 \\
Forest 2C & 2 & 2.6 \\
Forest 3 & 44 & 57.2 \\
\hline
\end{tabular}

\section{Tartışma}

Çalışmamızda, varis dışı üst Gis kanaması nedeniyle gastroskopi yapılmış olan 231 hastayı geriye dönük olarak inceledik. Bu değerlendirmede üst GiS kanamasının daha sık olarak erkeklerde görüldüğünü ve ortalama $52.72 \pm 14.25$ yaşında meydana geldiğini tespit ettik. Çalışmamıza benzer şekilde daha önce yapılan bir çalışmada da yaş ortalaması benzer olarak bulunmuş (54.5) ve erkeklerde daha sık (\%68.7) olduğu tespit edilmiştir (7). Erkeklerde Gis kanamasının bayanlardan daha sık görülmesinin nedeni, hem bayanlarda premenopozal dönemdeki gastrik mukoza bütünlüğünün daha iyi olması, hem de erkeklerde komorbid hastalık miktarının kadınlardan daha fazla olmasına bağlı olabilir $(8,9)$. Ancak biz bu çalışmamızda komorbid hastaIıkları geriye olarak tarama yaptığımız için tespit edemedik. Hastaların komorbid hastalıklarını bilmek ve sunmak çalışmamıza ek katkı sağlayabilirdi.

Üst gastrointestinal sistem kanamalarının en sık nedeni ülserler iken ikinci sıklıkta eroziv gastrit yer alır(10). Baş ve ark.'nın (11) yapmış oldukları çalışmada ülserler \%58.4 oranıyla ilk sırada yer alırken, eroziv gastritler \%29.8 oranıyla ikinci sırada yer almıştır. Sezikli ve ark.'nın (12) yapmış oldukları çalışmada ilk sırada duodenal ülser yer almaktaydı. Yalçın ve ark. (4) ise \%63.2 oranında ülser, $\% 16.3$ oranında eroziv gastrit bildirmiştir. 230 hastanın yer aldığı bir çalışmanın analizinde gastroduedonal ülserlerin oranı \%71.2 olarak bulunmuştur (13). Thomopoulos ve ark.'nın (14) da gastrointestinal sistem kanama sebepleri içinde peptik ülserin birinci sırada yer almakta olduğunu ifade etmişlerdir. Literatür ile uyumlu olacak şekilde, biz de kendi çalışmamızda ilk sırada duodenal ülserin ve ikinci sırada eroziv gastrit vakalarının yer aldığını saptadık. Dolayısıyla elde ettiğimiz sonuçlar, mevcut literatür bilgilerini desteklemektedir.

2008 yılında Uyanıkoğlu A ve ark'nın (15) yaptığı çalışmada duodenal ülserin üst GiS kanamalarındaki oranı \%52.6 iken yıllar geçtikçe yapılan çalışmalarda bu oranın giderek azalmakta olduğunu görmekteyiz. Bizim çalışmamızda duodenal ülserlerin üst Gis kanamalarının \%35' ini oluşturduğunu ve üst gastrointestinal kanama sebepleri içinde 1.sıradaki yerini koruduğu gözlemlenmiştir. Duodenal ülser kanamasının diğer kanama sebepleri içindeki orantısal olarak azalması, Helicobacterpylori (Hp) eradikasyon tedavisindeki başarı artışının bir sonucu olarak değerlendirilebilir. Bugün için ülser etyolojisinde Helicobacterpylori ilk sıradadır ve bunu non steroid antiinflamatuvar ilaçlar (NSAii) izlemektedir. Ülser kanamasının kanama nedenleri içinde ilk sıraya yükselmesinin en büyük nedeni, Hp kolo- nizasyonunun ve NSAii kullanımının yaşla beraber artmasıyla açıklanabilir (16-18).

Antral gastrit endoskopik tetkik ile en sık tespit edilen endoskopik tanılardan biridir. Sonuçlarımız literatür verileriyle benzer bulunmuştur $(19,20)$. Üst GiS kanaması semptomlarıyla gelen hastada özofagogastroduodenoskopi altın standart tanı ve tedavi yöntemi olarak kabul edilmektedir (6). Üst GiS kanamalarında endoskopi kontrendikasyonları oldukça sınırlıdır (21). Endoskopi işlemi öncesinde premedikasyonda farenks anestezisi için topikal anestetikler ve/veya ek olarak midazolam uygulanmaktadır. Merkezimizdeki üst gastrointestinal sistem endoskopisi işlemleri, genel olarak topikal anestezi altında gerçekleştirilmiştir. Üst GiS endoskopisi sedasyon verilmeden yapıldığında kolay tolere edilebilen bir işlemdir ve topikal anestezinin yeterli olduğu söylenebilir. Çalışmamızda, işleme bağlı herhangi bir komplikasyona da rastlanmamıştır.

Varis dışı üst gastrointestinal kanama görülme sıklığının mevsimsel olarak değişkenlik gösterebildiği bildirilmiştir (22). Bizim serimizde başvuru en sık yaz aylarında, en az kış aylarında idi.

Hastaların tekrarlayan ülser kanama ihtimallerini tespit etmede kullanılan sınıflamalardan biri Forrest sınıflamasıdır.Ülserler endoskopik görünümlerine göre Forrest sınıflamasında şu şekilde sınıflanır: 1A, fışkırır tarzda aktif kanama, 1B, sızıntı tarzında aktif kanama, 2A, kanamayan görünür damar, $2 B$, yapışık pıhtı, $2 \mathrm{C}$, düz pigmente lezyon, 3 , kanama bulgusu yok $(23,24)$. Forrest $1 A, 1 B$ ve $2 A$ sınıfı ülserler endoskopik olarak tespit edilirse bu hastalara endoskopik tedavi yapılması gerekir. Forrest 2B olan hastalara ise sadece devam eden kanaması varsa endoskopik tedavi önerilmektedir.Ülser tabanına yapışmış olan pıhtı kaldırıldığında, bu ülserlerin \%30'unda aktif kanama veya görünen damar ortaya çıkabilir. Yine bu hastalara da endoskopik tedavi yapılması gerekir. Forrest $2 \mathrm{C}$ ve 3 ülserli olan hastalarda ise endoskopik tedavi endikasyonu yoktur (25). Ülkemizde duodenal ülserli hastaların endoskopik Forest sınıflamasıyla değerlendirildiği çalışmada en sık Forest 3 sınıfı ülserler tespit edilmiştir(4,26). Bir diğer 460 duodenal ülserli hastanın forest sınıflamasına göre değerlendirildiği çalışmada Forest 3 grubu hastalar \%63.2 oranınıyla ilk sırada yer almıştır (27). Bizim çalışmamızda da \%57.2 oranıyla Forrest 3 grubu hastaların ilk sırada yer aldığını tespit ettik ve bu sonuçlar literatür verileriyle uyumlu olarak görülmektedir.

Çalışmamızın en büyük kısıtlılığı hasta sayısının sınırlı olması ve çalışmanın geriye dönük bir çalışma olmasıdır. Ek olarak, hastaların bazal demografik özelliklerini, hemogram ve biyokimyasal parametrelerini ve komorbid hastalık durumlarını incelememiştik. Bu özelliklerin incelenmesi çalışmamıza ek katkı sağlayabilirdi.

\section{Sonuç}

Varis dışı üst GiS kanama erkeklerde daha sıktır. En sık neden duodenal ülserdir ve bu durum hastaların yaklaşık üçte birini oluşturmaktadır. En sık kanama başvurusu yaz, en az kış aylarında görülmektedir. 
Etik onam: Çalışma için Harran Üniversitesi Klinik Araştırmalar Etik Kurulundan etik onam alındı (17/08/2020 tarih ve HRU/20.14.01 sayılı karar).

\section{Yazar Katkıları:}

Konsept: NY

Literatür Tarama: MÖE

Tasarım: $A U, S C E$

Veri toplama: $M O ̈ E$

Analiz ve yorum: MÖE

Makale yazımı: MÖE, AU

Eleştirel incelenme: $A U$

Çıkar Çatışması: Yazarlar çıkar çatışması beyan etmemişlerdir. Finansal Destek: Yazarlar finansal destek beyan etmemişlerdir.

\section{Kaynaklar}

1. Jutabha R, Jensen DM. Acute upper gastrointestinal bleeding. In:Friedman SL, McQuaid KR, Grendell JH (eds). Current Diagnosis\&Treatment in Gastroenterology. 2nd ed. New York: McGraw-HillCo, 2003:53- 69.

2. Pulanic $R$, Vucelic $B$, Rosandic $M$. Comparison of injection sclerotherapy and laser photocoagulation for bleeding peptic ulcers. Endoscopy 1995;27:291-7.

3. Alican F. Abdomen: genel konular. Cerrahi Dersleri. 2. baskı. Cilt 1. İstanbul: Avrupa Tıp Kitapçık, 1998:419-91.

4. Yalçın MS, Kara B, Öztürk NA, Ölmez Ş, Taşdoğan BE, Taş A. Üst Gastrointestinal Sistem Kanamalı Hastaların Epidemiyolojisi ve Endoskopik Bulguları. Dicle Medical Journal 2016;43:73-6.

5. Seves I, Sousa C, Luz Z. Prognostic value of the finding of blood/clots in the stomach at the emergency upper endoscopy. Acta Med Port 2002;15:413-6.

6. Boonpongmanee S, Fleischer DE, Pezzullo JC, Collier K, Mayoral W, Al-Kawas F, et al. The frequency of peptic ulcer as a cause of upper-GI bleeding is exaggerated. Gastrointest Endosc 2004;59:788-94

7. Lambert R. Digestive endoscopy: relevance of negative findings. Ital J Gastroenterol Hepatol 1999;31:761-72.

8. Loperfido S, Monica F, Maifreni L. Bleeding peptic ulcer occuring in hospitalized patients: analysis of predictive and risk factors and comparison without of hospital onset hemorrhage. Dig Dis Sci 1994;39: 698-705.

9. 9. Palmer K. Acute upper gastrointestinal haemorrhage. $\mathrm{Br}$ Med Bull 2007;83: 307-24

10. Günsar F, Akarca US, Yönetçi N, Özütemiz Ö, Aydın A, Ersöz $\mathrm{G}$, ve ark. Üst gastrointestinal sistem kanamalı yüz hastanın değerlendirilmesi. Türk J Gastroenterol 1997;8:18893.

11. Baş B, Oymacı E, Dinç B. Evaluation of Results in Patients with Acute Upper Gis Bleeding: A Goverment Hospital Experience. J Clin Anal Med 2015;6:362-5

12. Sezikli M, Çetinkaya ZA, Bünül F, Şirin G Gastroskopi yapılan hastalarımızın bulgularının irdelenmesi Kocaeli Tıp Dergisi 2013;1:11-14 Medical Journal of Kocaeli 2013;1:11-14

13. Okutur SK, Alkım C, Bes C, Gürbüz D, Kınık Ö, Gültürk E ve ark. Akut üst gastrointestinal sistem kanamaları: 230 olgunun analizi. Akademik Gastroenteroloji Dergisi 2007;6:306.

14. Thomopoulos K, Vagenas K, Vagianos C, Margaritis VG, Blikas AP, Katsakoulis EC, et al. Changes in aetiology and clinical outcome of acute upper gastrointestinal bleeding during last 15 years. Eur J Gastroenterol Hepatol 2004;16:177-82

15. Uyanıkoğlu A, Danalığlu A, Davutoğlu C, Alimoğlu O, Baş B Akut Üst Gastrointestinal sistem kanaması:Endoskopi Sonuçlarının Rektrospektif Değerlendirilmesi İst TIp Fak Derg 2008;71:120-123

16. Pilotto A. A ging and upper gastrointestinal disorders. Best Pract Res Clin Gastroenterol. 2004;18:73-81.

17. Postiglione VR, Lippa M, Tonni MP, Balducci D, Pancaldi R, Morandi $\mathrm{O}$, et al. Hemorrhage of the upper digestive tract in the elderly patient: is the limit of 60 years of age still biologically valid? Statistical study]. Minerva Chir. 1995;50(3):247-52.

18. Uyanikoglu A, Danalioglu A, Akyuz F, Ermis F, Gulluoglu M, Kapran $Y$, et al. The etiological Factors of Duodenal and Gastric Ulcers. The Turkish Journal of Gastroenterology. 2012;23(2): 99-103.

19. Depolo A, Dobrila-Dintinjana R, Uravi M, Grbas H, Rubini M. Upper gastrointestinal bleeding - Review of our ten years results. Zentralbl Chir. 2001;126(10):772-6.

20. Vreeburg EM, Snel P, de Bruijne JW, Bartelsman JF, Rauws EA, Tytgat GN. Acute upper gastrointestinal bleeding in the Amsterdam area: incidence, diagnosis, and clinical outcome. Am J Gastroenterol 1997; 92:236-43.

21. Cappell MS. Gastrointestinal endoscopy in high-risk patients. Dig Dis 1996;14:228-44.

22. Uyanıkoğlu A, Davutoğlu C, Çakırca M, Danalıoğlu A. Peptik Ülser Sıklığı Azalıyor mu? [Is PepticUlcerIncidenceDecreasing?] Nobel Med 2009; 5(2): 15-17

23. Conrad SA. Acute upper gastrointestinal bleeding in critically ill patients: Causes and treatment modalities. Crit Care Med 2002;30:365-8.

24. Büyükuncu Y. Üst gastrointestinal sistem endoskopisi. Kalaycı G (ed). Genel Cerrahi.1. baskı. İstanbul: Nobel Tıp Kitabevleri 2002;2:1029-49.

25. British Society of Gastroenterology Endoscopy Committee. Non variceal upper gastrointestinal haemorrhage: guidelines. Gut 2002;51:iv1-iv6.

26. Cander B, Ertekin B, Kara H, Gül M, Dündar D, Koçak S, ve ark. Acil Servise Gastrointestinal Kanama ile Başvuran Hastalarda Hastane Yatış Süresini Etkileyen Faktörler. Fırat Tıp Dergisi 2011;16:51-4.

27. Cipolletta L, Bianco MA, Rotondano G, Marmo R, Riscopo R. Outpatient management for low-risk nonvariceal upper GI bleeding: A randomized controlled trial. Gastrointest Endosc 2002;55:1-5. 